\title{
Avaliação de técnicas de fusão de imagens orbitais utilizando produtos do satélite CBERS 4 para a APA do Rio Machado-MG
}

\author{
Fusion orbital images techniques evaluation using products of CBERS 4 satellite for APA of \\ Rio Machado-MG
}

\author{
Rodrigo José Pisani \\ Doutor em Geociências e Meio Ambiente e docente do curso de \\ Geografia da Universidade Federal de Alfenas - MG, Brasil \\ pisanigeo@gmail.com \\ Viviane Costa Bueno \\ Discente do curso de Geografia Bacharelado da \\ Universidade Federal de Alfenas - MG, Brasil \\ vivianecostabueno@ hotmail.com \\ Joice dos Reis Fiuza \\ Discente do curso de Geografia Bacharelado da \\ Universidade Federal de Alfenas - MG, Brasil \\ joicefiuza@yahoo.com.br \\ Paulo Vitor Moraes Estela \\ Discente do curso de Geografia Bacharelado da \\ Universidade Federal de Alfenas - MG, Brasil \\ paulo_v01@yahoo.com.br
}

\begin{abstract}
Resumo
As técnicas de fusão de imagens multiespectrais e pancromáticas se mostram como ferramentas valiosas para o aprimoramento da acuidade visual do ponto de vista da resolução espacial e, por consequência, do reconhecimento de feições de uso e cobertura da terra. O presente trabalho teve como objetivo a avaliação qualitativa e quantitativa de 3 métodos de fusão de imagens sendo o método IHS, Brovey e Simple Mean. Para tal foram utilizadas imagens do satélite CBERS 4, sensores MUX e PAN para o estudo de caso na Área de Proteção Ambiental do Rio Machado, região sul de Minas Gerais. Entre os resultados, destacam-se os melhores reconhecimentos do ponto de vista qualitativo para o método IHS e o melhor ajuste estatístico com o método Brovey com os menores valores de dispersão para a Regressão Linear. Com isso, conclui-se que, apesar dos resultados alcançados com as imagens obtidas e com os testes realizados, existe uma subjetividade na escolha do melhor produto, dada a escala utilizada e o objetivo proposto.
\end{abstract}

Palavras-chave: IHS, Brovey, Simple Mean.

\begin{abstract}
Fusion Techniques of multispectral and panchromatic images show as essential tools for the improvement of visual acuity of spatial resolution and, for a consequence, of recognition of features of land use and cover. The present research had as objective a qualitative and quantitative evaluation of 3 methods of image fusion from CBERS images satélites, with MUX and PAN sensors for the case study in Rio Machado Environmental Protection Area, South region of Minas Gerais State. The results shed light over better recognition rates for the IHS method and the quantitative result for Brovey method with lower dispersion values with Linear Regression. Conclusions: Despite the results and the adjustments reached in this research, there is subjectivity in the choice of better products from scale and the objective of the research.
\end{abstract}

Keywords: IHS, Brovey, Simple Mean. 


\section{INTRODUÇÃO}

O sensoriamento remoto apresenta-se como uma valiosa ferramenta de monitoramento e análise do meio físico como a análise multitemporal, detecção de áreas degradadas, avanço urbano, desastres naturais, entre outras. Para que essas condições ocorram, é preciso que existam condições que melhorem o processo de identificação de feições com uma acuidade visual satisfatória nas imagens orbitais. Entre as principais técnicas, pode se citar o processo de fusão de imagens multiespectrais e pancromáticas onde se aprimora a resolução espacial da mesma com uma composição satisfatória para a identificação de alvos com perdas mínimas de informação ou de degradação dessas imagens.

De acordo com Magalhães et al. (2011). Para um determinado estudo onde é necessário ter uma melhor nitidez, precisão e intervalo temporal do objeto de estudo, é imprescindível que as imagens de satélite adquiridas apresentem uma alta resolução espacial, espectral e temporal. Ainda de acordo com Matias et al. (2009) imagens de satélite ideais para estudos mais fidedignos devem ter alta resolução espectral, radiométrica, espacial e recobrir uma mesma área com pouco espaçamento temporal. A fusão de imagens possibilita a integração da resolução espacial da banda pancromática com a melhor resolução espectral das demais bandas, produzindo uma imagem colorida (sintética) que reúne as melhores características de ambas as imagens utilizadas no processo (LEONARDI et al., 2009).

Alguns trabalhos como o de Ferreira et al. (2015) testaram os métodos IHS e o de Componentes Principais para reconhecimento de feições urbanas no município de Três Lagoas-MS. No mesmo sentido, Pereira et al. (2016) utilizaram da técnica de fusão de imagens para definir melhores parâmetros de identificação de corpos d'água para cinco sensores diferentes. Outro trabalho interessante foi o de Fernandes, et al. (2013) que utilizaram da mesma abordagem para a identificação de fragmentos florestais em São José de Ubá-RJ. Com isso conclui-se que a técnica de fusão de imagens orbitais é consagrada em diferentes estudos, aplicações e técnicas visando a melhor identificação de feições na superfície terrestre, sobretudo aquelas ligadas ao uso e cobertura da terra.

Com isso o objetivo desse trabalho foi o de avaliar 3 métodos de fusão de imagens multiespecitrais e pancromáticas do satélite CBERS com os sensores MUX e PAN em uma região do sul de Minas Gerais, mais especificamente na Área de Proteção Ambiental - APA do rio Machado, comparando suas eficiências do ponto de vista qualitativo e quantitativo a fim de se recomendar os procedimentos de acordo com o reconhecimento de diferentes feições de uso da terra. 


\section{LOCALIZAÇÃO DA ÁREA DE ESTUDO}

A área de estudo está inserida na região da bacia hidrográfica do rio Machado e engloba sete municípios, sendo eles: Alfenas, Campestre, Ipuiuna, Machado, Poço Fundo, Pouso Alegre e Rio Capivari, dois deles Machado e Poço Fundo possui grande relação com o rio por fazer parte da área urbana (Figura 1). Com uma população estimada em aproximadamente 310.000 habitantes (IBGE, 2014), a bacia hidrográfica do rio Machado possui várias sub-bacias como as do Rio Sapucaí, do Rio das Mortes e do Rio Verde, tributários diretos da represa de Furnas que possui grande importância do ponto de vista hidrelétrico nacional, sendo seu monitoramento de grande relevância. A área de estudo compreende a aproximadamente $47 \mathrm{~km}^{2}$, e sua economia está fortemente ligada à agricultura do café.

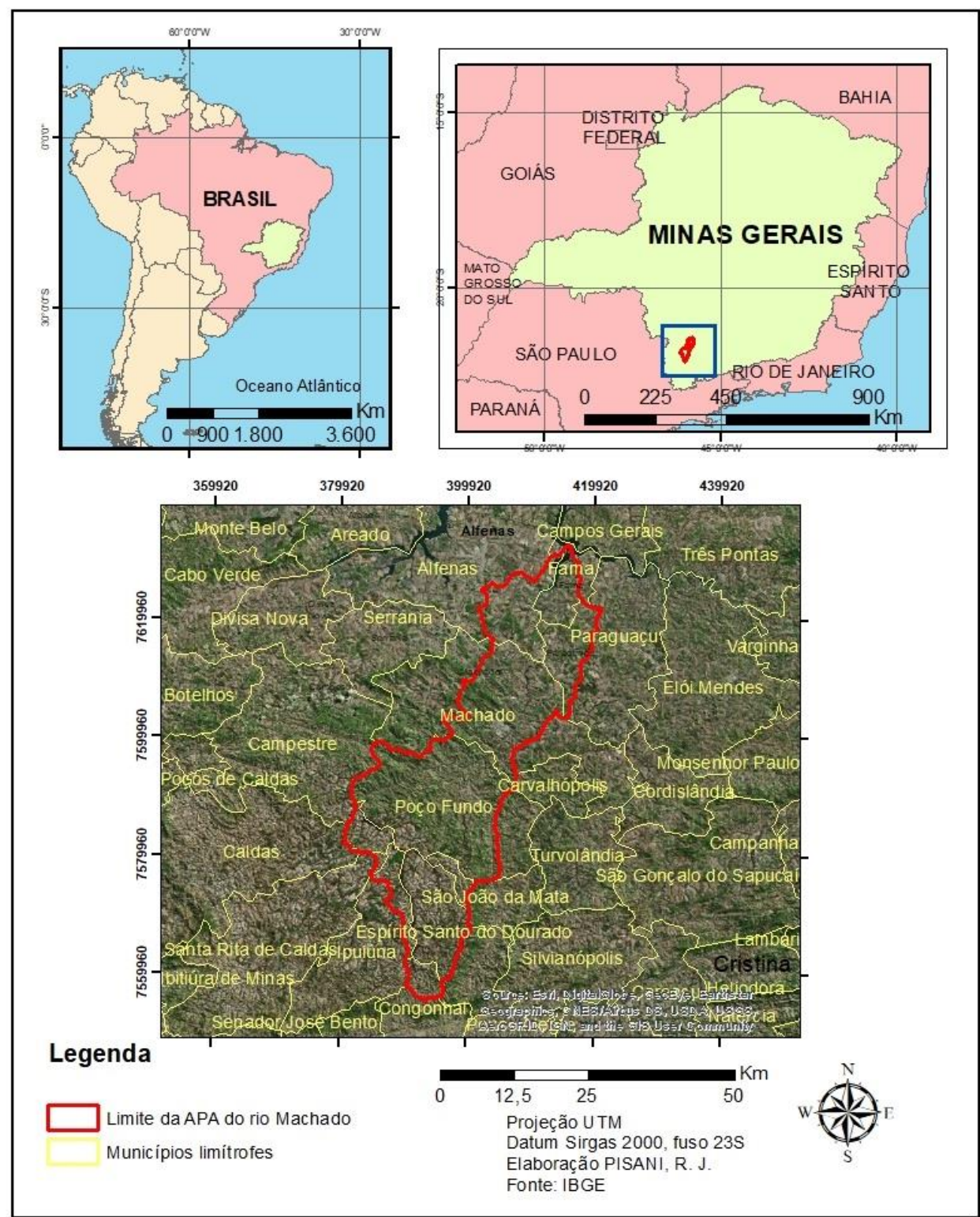

Figura 1. Área de estudo.

Fonte: Autores (2019) 


\section{MATERIAIS E MÉTODOS}

A pesquisa foi realizada sobre três imagens do satélite CBERS 4 com os sensores MUX de 20 metros de resolução espacial e duas imagens PAN de 5 metros de resolução espacial do dia 30/08/2017. Estas foram juntadas para o recobrimento da área de estudo pelo procedimento de mosaico de imagens. As imagens possuem resolução radiométrica de 8 bits em níveis de cinza e foram coletadas do site do INPE em www.inpe.br, que engloba a Área de Proteção Ambiental APA do rio Machado, região sul de Minas Gerais. A tabela 1 ilustra as características das imagens obtidas para o presente estudo:

Tabela 1. Características das imagens CBERS 4 para o presente estudo.

\begin{tabular}{l|l|l|l|l}
\hline \multicolumn{1}{c|}{ Satélite/Sensor } & \multicolumn{1}{c|}{ Data } & \multicolumn{1}{c|}{ Orbita/ponto } & \multicolumn{1}{c}{ Resolução } & \multicolumn{1}{c}{ Fonte } \\
\hline CBERS4/MUX & $30 / 08 / 2017$ & $154 / 124$ & $20 \mathrm{~m}$ & INPE $^{1}$ \\
\hline CBERS4/MUX & $30 / 08 / 2017$ & $154 / 125$ & $20 \mathrm{~m}$ & INPE $^{1}$ \\
\hline CBERS4/MUX & $30 / 08 / 2017$ & $155 / 125$ & $20 \mathrm{~m}$ & INPE $^{1}$ \\
\hline CBERS4/PAN & $30 / 08 / 2017$ & $155 / 124$ & $5 \mathrm{~m}$ & INPE $^{1}$ \\
\hline CBERS4/PAN & $30 / 08 / 2017$ & $155 / 125$ & $5 \mathrm{~m}$ & $\mathrm{INPE}^{1}$ \\
\hline
\end{tabular}

${ }^{1}$ Instituto Nacional de Pesquisas Espaciais, autores (2019).

As imagens selecionadas foram pré-processadas, contrastadas e compostas sendo que que a melhor composição que atendeu os objetivos da pesquisa foram a 5 (azul), 8 (infra vermelho próximo) e 7 (vermelho) nos canais em RGB. Posteriormente foram aplicadas as técnicas de fusão propostas na pesquisa, sendo as seguintes: IHS, Brovey e Simple Mean realizadas na plataforma ArcGIS 10.5.1. Neste trabalho foram comparadas as imagens antes e depois da fusão em termos qualitativos, ou seja, com superestimação e subestimação de informações no reconhecimento e separabilidade de feições de uso e cobertura da terra nas imagens híbridas.

Do mesmo modo, foram feitas avaliações quantitativas com o método de análise de pares de variáveis em regressão linear simples, ao avaliar os níveis de cinza nos canais $\mathrm{R}, \mathrm{G}$ e B das imagens compostas antes e depois a partir da análise em 50 pontos aleatórios coletados na imagem. $\mathrm{O}$ índice $\mathrm{R} 2$ varia entre 0 e 1 onde mais próximo a 1 mais similaridade e o contrário quanto mais próximo a 0. A distância mínima entre os pontos foi de 3000 metros para evitar enviesamento das amostras. A Figura 2 ilustra a localização dos pontos amostrados com as etapas desenvolvidas e a Figura 3 ilustra o fluxograma com as etapas realizadas na pesquisa em questão. 


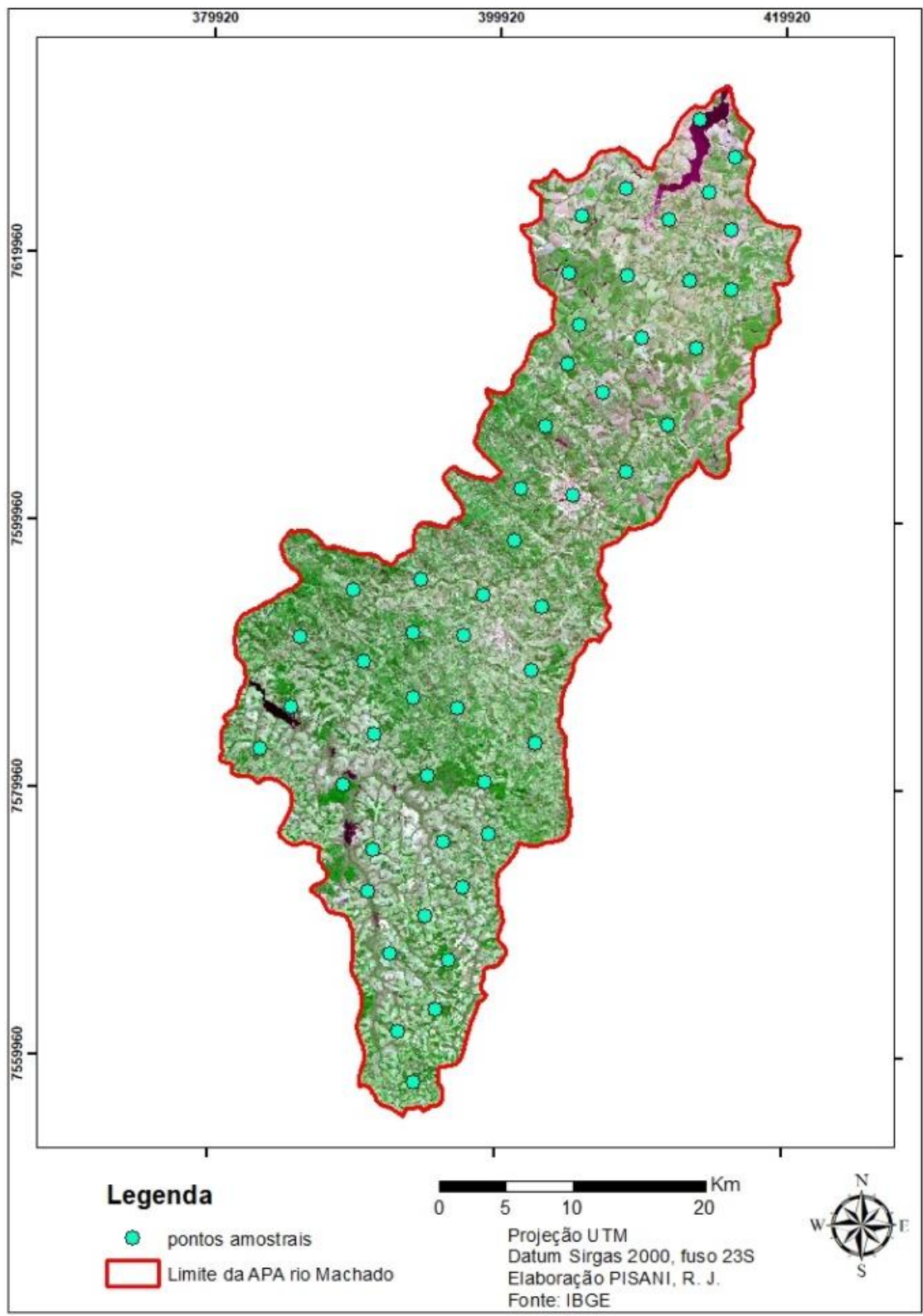

Figura 2. Pontos aleatórios coletados na área de estudo para análise quantitativa.

Fonte: Autores, 2019.

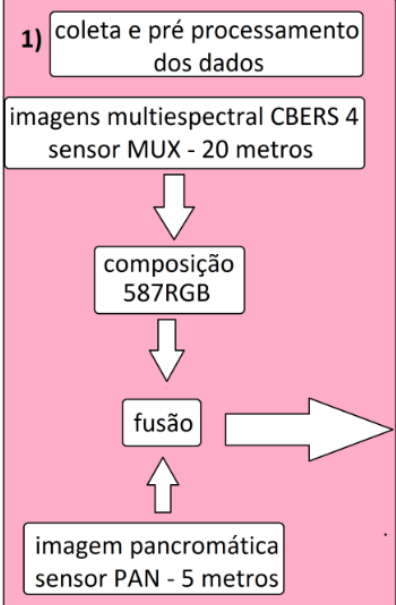

2) Análise e interpretação das informações

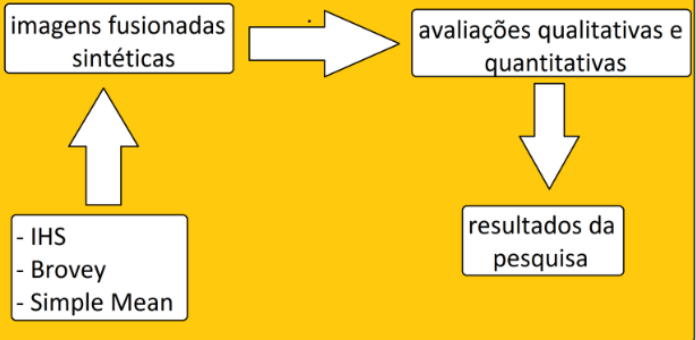

Figura 3. Fluxograma das etapas realizadas.

Fonte: Autores, 2019. 


\subsection{Técnicas de Fusão de Imagens}

De acordo com Pinho et al. (2005) as técnicas de fusão podem ser divididas em três grupos distintos: as que usam um modelo de domínio espacial, de domínio espectral e que abordam operações algébricas. Ainda de acordo com os mesmos autores as técnicas de modelos espaciais isolam a informação espacial de alta frequência provenientes da imagem de alta resolução e a combinam com a imagem multiespectral. O grupo de modelos de domínio espectral é formado pelos processos que realizam uma transformação na imagem multiespectral, resultando num novo conjunto de bandas onde uma delas é correlacionada com a imagem pancromática, e os modelos algébricos realizam funções aritméticas pixel-a-pixel (MAGALHÃES, 2011). É importante destacar que as técnicas de fusão de imagens realizadas para esta pesquisa foram elaboradas a partir da reamostragem da banda multiespectral com menor resolução espacial para em seguida transformá-la em uma imagem híbrida com maior resolução espacial a partir da fusão de imagens com a banda pancromática de maior resolução espacial. O Quadro 1 apresenta todas as técnicas utilizadas para o desenvolvimento do presente trabalho.

Quadro 1. Produtos utilizados para a fusão de imagens.

\begin{tabular}{|c|c|c|c|}
\hline \multirow{2}{*}{ Satélite } & \multicolumn{3}{|c|}{ Técnicas de fusão } \\
\cline { 2 - 4 } & IHS & Simple mean & Brovey \\
\hline \multirow{2}{*}{$\begin{array}{c}\text { Imagem CBERS 4 } \\
\text { bandas 578 }\end{array}$} & Fusão 1 & Fusão 2 \\
\cline { 2 - 4 } & Banda PAN & Banda PAN & Banda PAN \\
& (5 metros) & $(5$ metros $)$ & (5 metros) \\
\hline
\end{tabular}

Autores, 2019.

\subsection{Transformação IHS}

De acordo com Crosta (1992) o procedimento IHS visa projetar a informação de cores representadas no espaço vermelho, verde e azul (RGB) para outro conjunto de eixos de medição de cores. Ainda de acordo com o mesmo autor, o sistema IHS possui a vantagem de apresentar as cores de uma forma mais aproximada àquela utilizada pelo sistema de visão humano, pois os tons são descritos em termos de Intensidade, Matiz e Saturação.

A transformação IHS permite um maior controle individual sobre os componentes cromáticos (Matiz) e acromáticos (Saturação) da imagem. O sistema IHS pode ser representado por um cone onde a Intensidade refere-se à distância de origem ou ápice do cone, a Matiz à sequência radial ao redor dos círculos de saturação e do eixo de intensidade e a Saturação à distância radial do ponto até o eixo central do cone (SANTOS et al., 2010). Por serem independentes, os três 
parâmetros podem ser analisados e modificados separadamente para um melhor ajuste das cores às características do sistema visual por meio da utilização de diferentes sensores e resolução espacial. A intensidade pode ser calculada conforme a equação 1 .

$$
I=V B P-V B I V P * P B I V
$$

em que:

I: intensidade;

VBP: valor da banda pancromática;

VBIVP: valor da banda do infra-vermelho próximo;

PBIV: peso da banda do infra-vermelho próximo.

Em relação a transformação Simple Mean, esta consiste na aplicação de uma equação de média aritmética simples para cada combinação de bandas de saída (MAGALHÃES, 2011). Utiliza o valor médio entre o vermelho, verde e azul e valores de pixel da imagem pancromática, conforme equação 2:

em que:

$$
V B F=\frac{(V B O+V B P)}{2}
$$

VBF: valor da banda fusionada;

VBO: valor da banda original;

VBP: valor da banda pancromática

A transformação do tipo Brovey consiste numa combinação aritmética entre uma imagem multiespectral de baixa resolução espacial representada no espaço $R G B$ e uma imagem pancromática de alta resolução. Nessa transformação, cada banda da imagem multiespectral é dividida pela soma das bandas da imagem multiespectral multiplicadas pela banda pancromática, conforme equação 4 (ESRI, 2019). A fusão BROVEY e a IHS possuem duas limitações semelhantes, em que, o número de bandas serem utilizadas é restrita a apenas três imagens híbridas de saída com resolução radiométrica de 8 bits, pois trabalha no sistema de cores RGB.

$$
V B F=\frac{V B O}{\left(V B_{R}+V B_{G}+V B_{B}\right) * V B P}
$$

em que:

VBF: valor da banda fusionada;

VBO: valor da banda original;

VBR: valor da banda vermelha;

VBG: valor da banda verde;

VBB: valor da banda azul;

VBP: valor da banda pancromática. 


\section{ANALISE QUALITATIVA E QUANTITATIVA}

As avaliações dos procedimentos adotados para a fusão de imagens que resultam diretamente na resolução espacial das imagens a fim de se melhorar a acuidade visual das mesmas e possibilitar com isso melhor reconhecimento de feições pode ser feita de modo qualitativo e quantitativo. Do ponto de vista qualitativo podem ser analisados os reconhecimento de feições de uso da terra e sua respectiva similaridade em temos de subestimação e superestimação das informações contidas nessas feições. Em relação às análises quantitativas estas podem ser estimadas por meio de análise de pares de variáveis para se avaliar as imagens, do ponto de vista radiométrico, antes e depois do processo de fusão. Para o presente trabalho buscou-se identificar as similaridades dos valores radiométricos pela regressão linear onde, quando existe mais similaridades entre as informações, o valor R se aproxima de 1 em uma escala de 0 a 1 e o contrário, ou seja, quanto mais distante de 1 e próximo a zero, observa-se dissimilaridades entre o real e o observado, sendo nesse caso, os valores das bandas antes da fusão e depois do processo de fusão.

\subsection{Resultados alcançados}

Observou-se a priori com os métodos de fusão utilizados as imagens com melhor reconhecimento de feições e melhor similaridade do ponto de vista qualitativo em comparação com as imagens originais. De acordo com a Figura 4 o produto que mais teve similaridade mais satisfatória foi o IHS (B) no reconhecimento, por exemplo, de feições de pastagem. Nota-se que os produtos representados em C e D, ou seja, Brovey e Simple Mean existe uma homogeneização das classes o que de certa forma difere da imagem original (A) a qual ilustra uma diferenciação na classe em questão que ilustra possivelmente uma pastagem degradada em uma mistura de vegetação rasteira e solo exposto.

Em relação à Figura 5 é possível se visualizar a diferenciação da feição de área urbana do município de Machado-MG e sua diferenciação com as demais feições de uso da terra. Do mesmo modo, do ponto de vista qualitativo, nota-se que em A, ou seja, no método IHS existe uma melhor diferenciação da classe citada com a demais, evitando-se assim uma confusão na diferenciação das feições. No método B (Brovey) destaca-se uma maior homogeneidade entre as classes de pastagem com as áreas de solo exposto notadas em tonalidades em azul. Nota-se que em C (método Simple Mean) existem pontos com tonalidades mais claras, superestimando os valores de reflectância em regiões que possivelmente possam estar associadas a telhados metálicos e complexos industriais. 


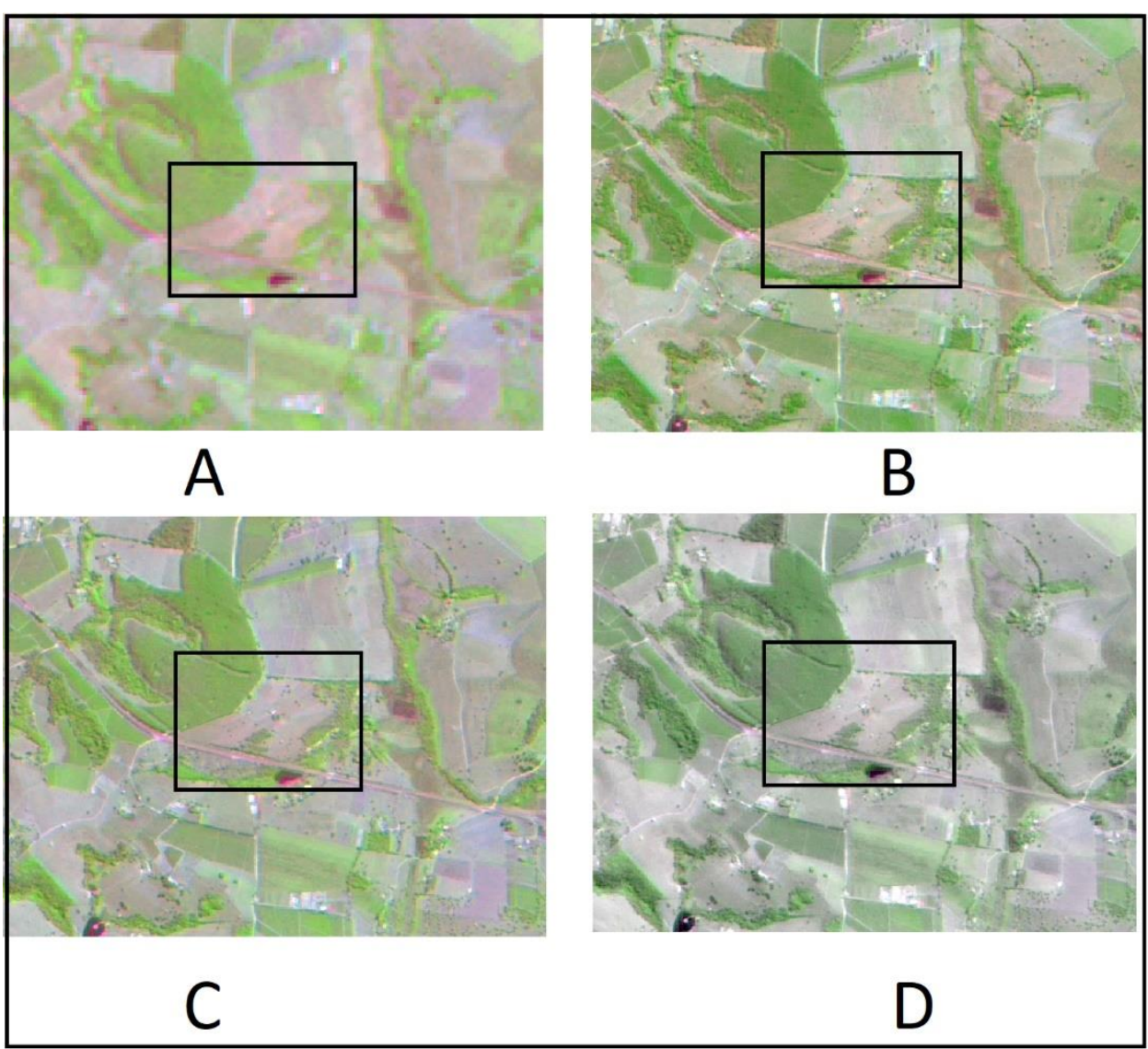

Figura 4. Imagem original em A e em B, C e D respectivamente as fusões IHS, Brovey e Simple Mean.

Fonte: Autores, 2019.

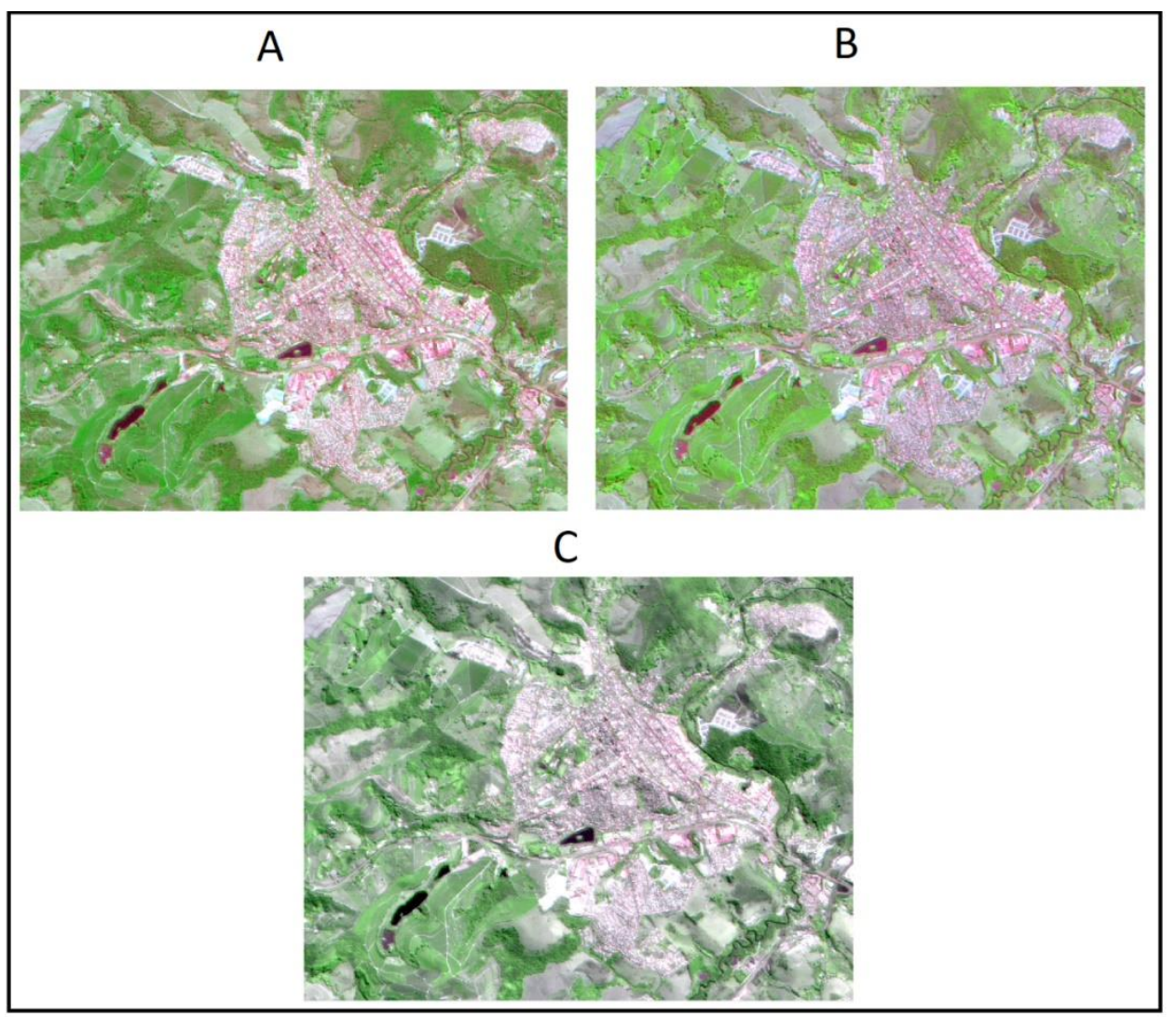

Figura 5. Técnicas IHS, Brovey e Simple Mean ilustradas respcetivamente em A, B e C para ilustração da mancha urbana de Machado-MG.

Fontes: Autores, (2019). 
Do ponto de vista quantitativo, conforme dito na seção anterior foi testada a correlação com os pares de variáveis das imagens antes e após o processo de fusão nos canais RGB das mesmas. A Figura 6 ilustra o resultado da análise para o método IHS:

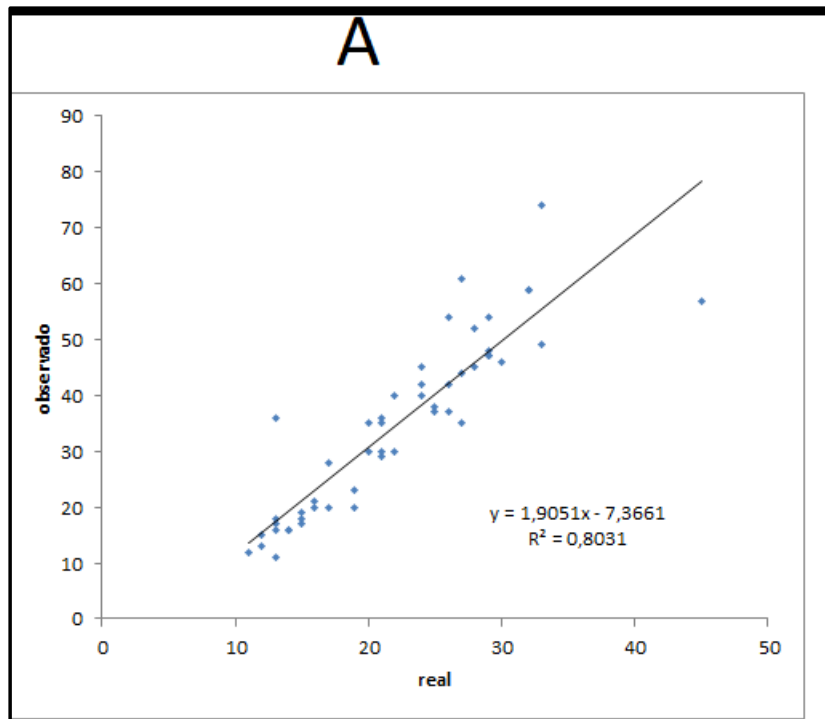

B

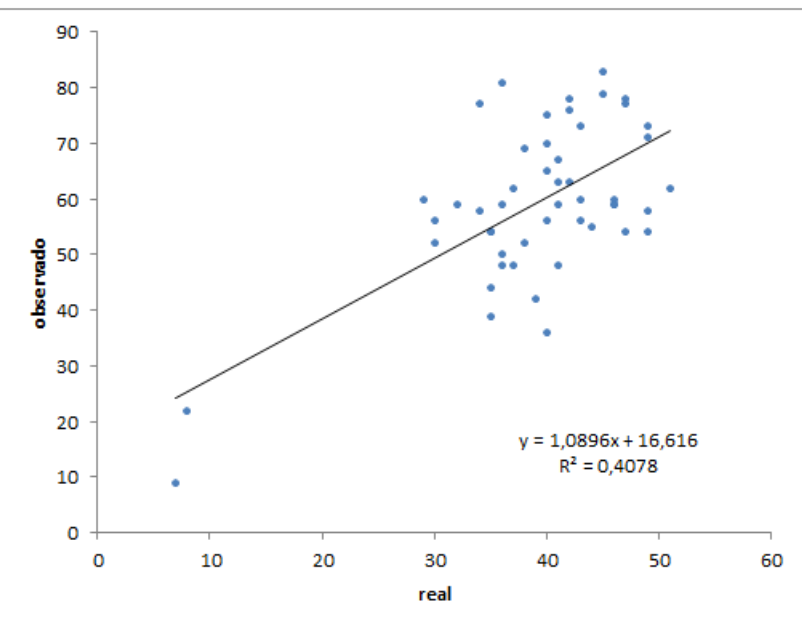

C

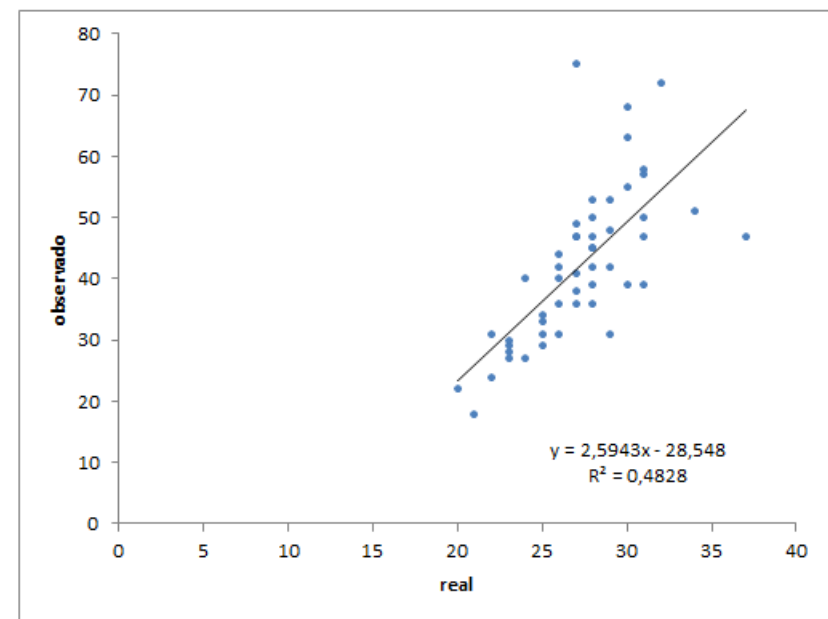

Figura 6. Regressão Linear com os pares de variáveis das imagens originais e fusionadas de acordo com os canais R, G e B em tons de cinza para o método IHS.

Fonte: Autores, 2019.

O método IHS obteve um satisfatório índice de similaridade com o canal R (C) da imagem em relação aos tons de cinza da imagem original (real) e pós processo de fusão pelo método IHS (observado) com valor de 0,8051. Em relação aos canais G e B (letras B e C) os resultados foram similares com valor ligeiramente maior no canal B com 0,4828 (letra C). Em seguida foram obtidos os valores de similaridades pelo método Brovey, conforme ilustra a Figura 7: 


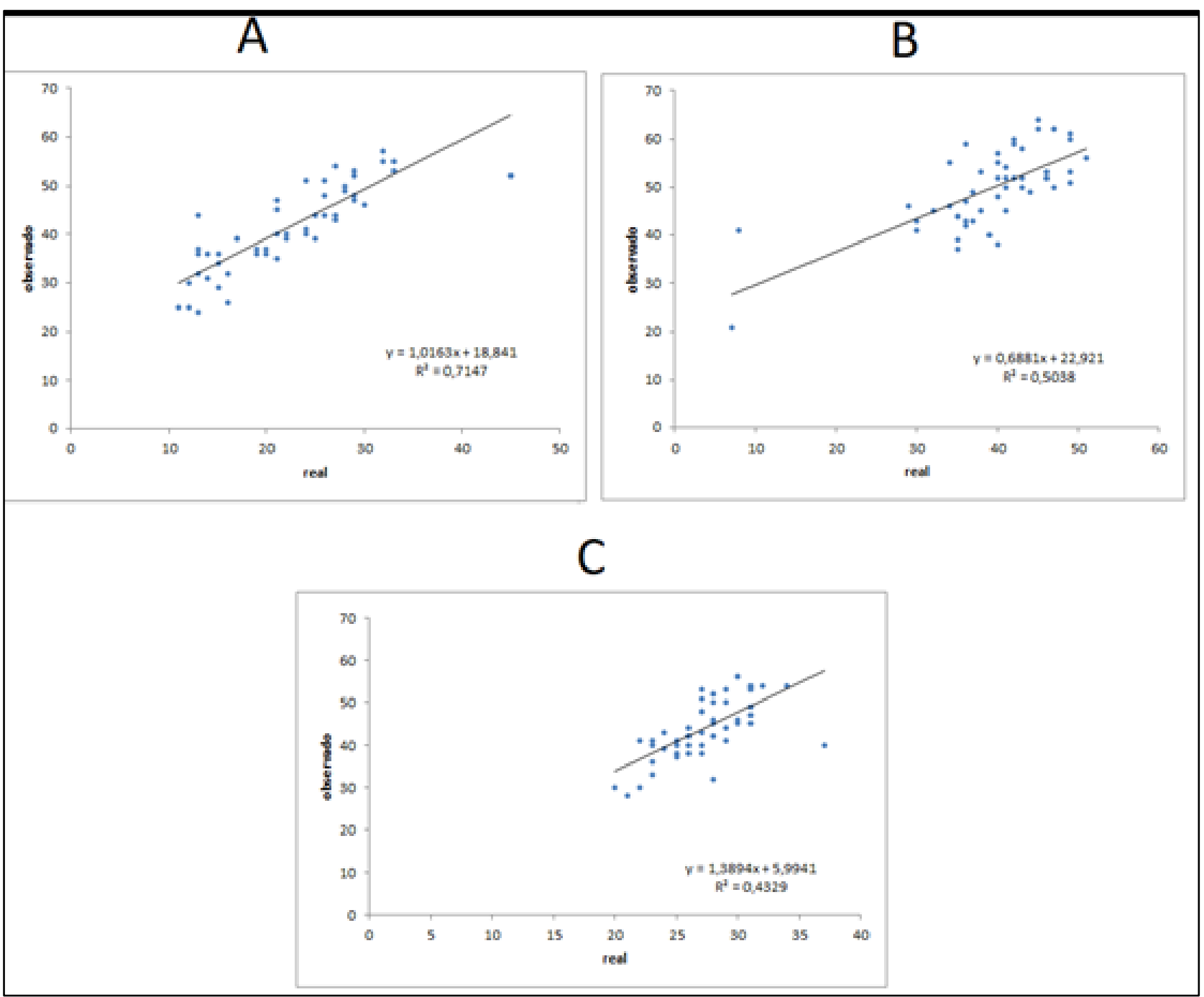

Figura 7. Regressão Linear com os pares de variáveis das imagens originais e fusionadas de acordo com os canais R, G e B em tons de cinza para o método Brovey.

Fonte: Autores, 2019.

Em relação ao método Brovey, obteve-se também um valor satisfatório com o canal R (A) com boa similaridade em relação à imagem original (real) e a simulada (ou observada) com índice de correlação de 0,7147. Do mesmo modo anterior, nos canais G e B (letras B e C) foram obtidos índices menores, porém com resultados melhores em relação ao método IHS com valores de 0,5038 e 0,4329 .

Em relação ao método Simple Mean (Figura 8) foram obtidos bons resultados em R e G (letras A e B) com valores de 0,7464 e 0,6678. Entretanto no canal B (letra C) foi obtida a pior similaridade entre os 3 métodos analisados com o valor de 0,187. Com isso pode-se afirmar que o melhor método em termos de "custo benefício" para a similaridade entre as bandas originais e processadas método de fusão, para a presente pesquisa, foi o método Brovey, sendo recomendado para fusões de imagens, no caso, a imagem CBERS 4 com o sensor MUX de 20 metros com o sensor PAN de 5 metros. O resultado é uma imagem com 5 metros de resolução espacial com área mínima mapeável de 25 metros quadrados, sendo um bom produto para mapeamentos temáticos. 
Entretanto tem de se levar em conta a análise qualitativa que, muitas vezes, por ser subjetiva e variar de analista para analista, neste estudo, o método que mais encaixou com as expectativas de reconhecimento de feições de uso e cobertura da terra foi o método IHS.

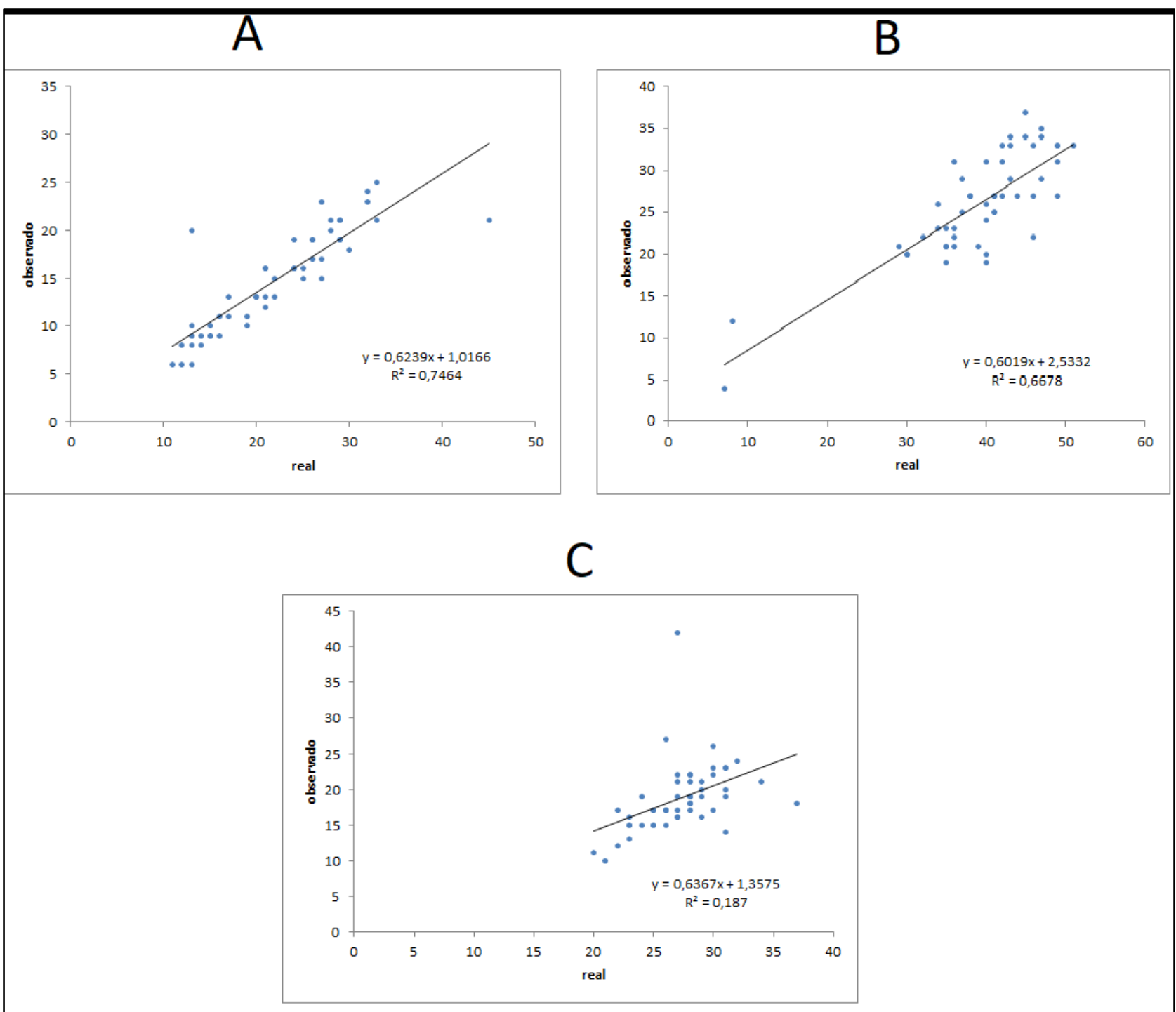

Figura 8. Regressão Linear com os pares de variáveis das imagens originais e fusionadas de acordo com os canais R, G e B em tons de cinza para o método Simple Mean.

Fonte: Autores, 2019.

\section{CONCLUSÕES}

Existem diferentes métodos de fusão de imagens multi espectrais e pancromáticas onde nesse trabalho foram testados os métodos IHS, Brovey e Simple Mean visando melhorar o reconhecimento de feições de uso e cobertura da terra tendo como estudo de caso a APA do Rio Machado, na região sul de Minas Gerais, sendo que para tal os métodos mais satisfatórios do ponto de vista quantitativo foi o método Brovey por ter apresentado menos dispersão dos valores 
quantitativos em temos de canais em relação aos outros métodos. Do ponto de vista qualitativo o IHS apresentou os resultados mais satisfatórios.

A escolha do método a ser empregado vale-se principalmente do objetivo que é proposto, e principalmente em relação a escala em que irá se trabalhar, sendo que a escolha do melhor produto qualitativo é algo subjetivo, ou seja, que pode variar de analista para analista. Sem dúvida a disponibilidade dos atuais produtos CBERS na plataforma do Instituto Nacional de Pesquisas Espaciais INPE vem a contribuir em muito a iniciativa de mapeamentos temáticos das mais diferentes naturezas ao ter boa qualidade e ser gratuito.

\section{REFERÊNCIAS}

CRÓSTA, A. P. Processamento digital de imagens de sensoriamento remoto. 1992. Ed. rev. Campinas. IG/Unicamp. 170p.

ESRI. ArcGIS - ArcMap 10.5, help on line. Disponível em: <http://help.arcgis.com/en/ arcgisdesktop/10.0/help/index.html\#//0017000000 9r000000>. Acesso em: 1 abr. 2019.

INSTITUTO NACIONAL DE PESQUISAS ESPACIAIS. Catálogo de imagens CBERS. São José dos Campos, 2019. Disponível em: www.dgi.inpe.br.

FERNANDES, P. J. F.; GIRÃO, R. S.; SILVA. L. C. Técnicas de processamento digital de imagens e mineração de dados aplicadas ao mapeamento de fragmentos florestais a partir de imagens ETM+. Cadernos de Estudos Geoambientais. v.4, n.1, 2013.

FERREIRA, C. C.; PIROLI, E. L.; SAKAMOTO, A. Y. Análise comparativa de fusão de imagens dos sensores orbitais CCD e HRC utilizando IHS e Componentes Principais na região urbana do município de Três Lagoas MS/BR. Periódico Eletrônico Fórum Ambiental da Alta Paulista v.11, n. 5, 2015.

LEONARDI, F.; OLIVEIRA, C. G.; FONSECA, L. M. G.; ALMEIDA, C. M. Fusão de Imagens CBERS 2B: CCD-HRC. In: SIMPÓSIO BRASILEIRO DE SENSORIAMENTO REMOTO, 14., 2009, Natal. Anais..., Natal: INPE, 2009, p. 6951-6958.

MAGALHÃES, I. A. L.; QUINTO, V. M.; PENA, F. E. R.; OMENA, M. S.; CHIBA, M. L.; SANTOS, A. R. Análise Comparativa entre técnicas de fusão de imagens de alta resolução espacial do Satélite Quickbird. Caderno de Geociências. v. 8, n. 2. Novembro de 2011.

MATIAS, L. F.; CAPORUSSO, D.; CRUZ, J. R. da; CARVALHO, J. C. B. de. Análise comparativa de técnicas de fusão de imagens CBERS-2B (CCD e HRC) utilizando o software ArcGIS. In: SIMPÓSIO BRASILEIRO DE SENSORIAMENTO REMOTO, 14., 2009, Natal. Anais..., Natal: INPE, 2009, p. 2071-2077. MOREIRA, M. A. (Coord.).Fundamentos do Sensoriamento Remoto e Metodologias de Aplicação. Viçosa, MG: $3^{\circ}$ ed. Viçosa - UFV, 2005, p. 250.

PEREIRA, L. E.; LATORIA, G.; FILHO, A. C. P; JUNIOR, J. M. Aplicação de Técnicas de Processamento Digital de Imagens em Diferentes Sensores Orbitais. Anuário do Instituto de Geociências - UFRJ. v. 39, n. 3, 2016. 
PINHO, C. M. D.; RENNÓ, C. D.; KUX, H. J. H. Avaliação de técnicas de fusão aplicadas à imagem Quickbird. In: SIMPÓSIO BRASILEIRO DE SENSORIAMENTO REMOTO, 12., 2005, Goiânia. Anais..., Goiânia: INPE, 2005, p. 4225- 4232. 2005.

SANTOS, A. R.; PELUZIO, T. M. de O.; SAITO, N. S. (Coord.). SPRING 5.1.2 passo a passo: aplicações práticas. Alegre, ES: Ciências Agrárias Universidade Federal do Espírito Santo/CAUFES, 2010, 155 p.

Trabalho enviado em 25/05/2019 Trabalho aceito em 25/06/2019 